\title{
RESISTÊNCIA DE CULTIVARES DE FEIJOEIRO-COMUM À FERRUGEM E À MANCHA-ANGULAR EM CONDIÇÕES DE CASA DE VEGETAÇÃO *
}

\author{
FÁBIO G. FALEIRO**1, SÍLVIA NIETSCHE**1, VILMAR A. RAGAGNIN ${ }^{1}$, ALUÍZIO BORÉM², MAURILIO A. \\ MOREIRA $^{1,3}$ \& EVERALDO G. DE BARROS ${ }^{1,4}$
}

${ }^{1}$ Instituto de Biotecnologia Aplicada à Agropecuária, ${ }^{2}$ Departamento de Fitotecnia, ${ }^{3}$ Departamento de Bioquímica e Biologia Molecular, ${ }^{4}$ Departamento de Biologia Geral, Universidade Federal de Viçosa, CEP 36571-000, Viçosa, MG

(Aceito para publicação em 22/11/2000)

Autor para correspondência: Everaldo G. Barros

FALEIRO, F.G., NIETSCHE, S., RAGAGNIN, V.A., BORÉM, A., MOREIRA, M.A. \& BARROS, E.G. Resistência de cultivares de feijoeirocomum à ferrugem e à mancha-angular em condições de casa de vegetação. Fitopatologia brasileira 26:86-89. 2001.

\section{RESUMO}

Foram inoculadas 17 cultivares de feijoeiro-comum (Phaseolus vulgaris) recomendadas para plantio em Minas Gerais com cinco patótipos $(6,7,9,10$ e 12) de Uromyces appendiculatus e cinco $(63.55,31.23,63.39,31.55$ e 63.23) de Phaeoisariopsis griseola. Foi conduzido um ensaio separadamente para cada um dos patótipos dos dois patógenos, totalizando 10 ensaios. Nos ensaios de ferrugem foi avaliada a frequiência de infecção (FI) e estimado o tamanho médio das pústulas (TMP) e, nos ensaios de mancha-angular foram avaliados os sintomas utilizando uma escala de notas variando de 1 a 9. A maioria das cultivares se mostrou suscetível a pelo menos três dos cinco patótipos de ferrugem. As cultivares mais suscetíveis foram Roxo 90 e Meia Noite e a mais resistente foi a Ouro Negro, a qual apresentou proteção completa aos cinco patótipos testados. Com relação à mancha angular, além do Roxo 90, as cultivares Carioca MG, Pérola, Carioca 1030 e Aporé, extensivamente plantadas em Minas Gerais, foram altamente suscetíveis. As cultivares Ouro Negro e EMGOPA 201-Ouro apresentaram genes de resistência a diferentes patótipos e a combinação desses genes em uma nova cultivar resultaria em resistência a todos os patótipos testados.

Palavras-chave: Uromyces appendiculatus, Phaeoisariopsis griseola, Phaseolus vulgaris, patótipos, resistência múltipla.

\section{ABSTRACT \\ Resistance of common bean to rust and angular leaf spot under greenhouse conditions}

Seventeen common bean cultivars recommended for Minas Gerais state, Brazil, were inoculated with five pathotypes $(6,7,9,10$ and 12) of Uromyces appendiculatus and five pathotypes $(63.55,31.23,63.39,31.55$ and 63.23$)$ of Phaeoisariopsis griseola. Five experiments were carried out for each pathogen. For rust, infection frequency (IF) and average pustule size (APS) were estimated. Angular leaf spot symptoms were evaluated using a 1 to 9 grading scale. The majority of the cultivars were susceptible to at least three pathotypes of $U$. appendiculatus. The most susceptible cultivars to rust were Roxo 90 and Meia Noite, and the most resistant was Ouro Negro, which was immune to all pathotypes tested. Roxo 90, Carioca MG, Pérola, Carioca 1030 and Aporé, which are extensively planted in Minas Gerais State, were widely susceptible to angular leaf spot. Cultivars Ouro Negro and EMGOPA 201Ouro harbor resistance genes to different pathotypes of $P$. griseola and, the combination of these genes in a new cultivar would result in resistance to all tested pathotypes.
As doenças que ocorrem na cultura do feijoeiro (Phaseolus vulgaris L.) constituem uma das principais causas da sua baixa produtividade no Brasil. A ferrugem, causada por Uromyces appendiculatus (Pers.) Unger var. appendiculatus e a mancha-angular, causada por Phaeoisariopsis griseola (Sacc.) Ferraris, podem causar sérios prejuízos, principalmente, durante os meses de abril a julho, quando são observadas, nas principais regiões produtoras, temperaturas amenas e ocorrência de orvalho (Paula Júnior \& Zambolim, 1998).

\footnotetext{
$\overline{* P A D C}$ T/FINEP e FAPEMIG

**Bolsista da CAPES e CNPq.
}

É fundamental que o controle dessas doenças seja feito de forma integrada, tendo em vista as características desses patógenos. A utilização de cultivares resistentes tem sido considerada um método eficiente, seguro, barato e acessível, no entanto, o desenvolvimento de cultivares resistentes é dificultado pela grande variabilidade de $U$. appendiculatus (Faleiro, 1997; Faleiro et al., 1998) e de P. griseola (Pastor-Corrales e Jara, 1995; Nietsche, 1997a). A característica, responsável pela "quebra" da resistência das cultivares, explica o alto potencial adaptativo destes patógenos.

Algumas cultivares de feijoeiro recomendadas pelo Sistema Estadual de Pesquisa Agropecuária de Minas Gerais 
Resistência de cultivares de feijoeiro-comum à ferrugem...

para plantio no Estado são suscetíveis à ferrugem (Faleiro et al., 1996) e à mancha-angular (Nietsche et al., 1997b). Desta forma, objetivou-se neste trabalho avaliar a resistência múltipla à ferrugem e à mancha-angular das principais cultivares de feijão recomendadas para Minas Gerais.

Sementes de 17 cultivares de feijão (Tabela 1), fornecidas pela EPAMIG (Empresa de Pesquisa Agropecuária de Minas Gerais), foram semeadas em vasos de 2,5 1 em casa de vegetação. Nove plantas de cada cultivar foram inoculadas com cada um dos cinco patótipos $(6,7,9,10$ e 12) de $U$. appendiculatus identificados por Faleiro (1997) e dos cinco patótipos $(63.55,31.23,63.39,31.55$ e 63.23$)$ de $P$. griseola identificados por Nietsche (1997a). Esses patótipos são os mais prevalecentes e virulentos em Minas Gerais (Faleiro, 1997; Nietsche,1997a).

A inoculação com ferrugem foi realizada quando as folhas primárias apresentavam aproximadamente $2 / 3$ do seu desenvolvimento completo, cerca de 10 dias após a semeadura. Foram aplicados 2,0 x 104 uredosporos/ml (Davison \& Vaughan, 1964) suspensos em água destilada contendo $0,05 \%$ de Tween 20, em ambas as superfícies foliares, com o auxílio de um atomizador manual do tipo De Vilbiss no 15 , acionado por um compressor elétrico, evitando-se atingir o ponto de escorrimento (Carrijo et al., 1980). Em seguida, as plantas foram levadas à câmara de nevoeiro $\left(20 \pm 1{ }^{\circ} \mathrm{C}\right.$ e umidade relativa $>95 \%$ ), onde permaneceram por $48 \mathrm{~h}$, sob fotoperíodo de 12 h. Foram, então, transferidas para casa de vegetação, permanecendo aí até a avaliação dos sintomas.

Foi avaliada a freqüência de infecção (FI) aos 12 dias após a inoculação, determinando-se o número de pústulas/ $\mathrm{cm}^{2}$, e estimado o tamanho médio de pústulas (TMP), quando $50 \%$ das mesmas encontravam-se esporulando. Na avaliação dos sintomas foram considerados seis graus de reação (Stavely et al., 1983). O grau de reação foi determinado mediante observação visual das pústulas na face superior das folhas primárias. Foram registrados todos os graus observados, relacionando-se primeiro o grau predominante e, a seguir, os presentes em menor freqüência.

Nos ensaios de mancha-angular, a inoculação foi realizada quando a primeira folha trifoliolada atingiu $2 / 3$ do seu desenvolvimento, cerca de 20 dias após a semeadura. $\mathrm{Na}$ inoculação das plantas foi utilizada uma concentração de inóculo ajustada para $2,0 \times 10^{4}$ conídios/ml suspensos em água destilada. Os procedimentos de inoculação, transferência para a câmara de nevoeiro e para a casa de vegetação foram idênticos aos realizados nos ensaios de ferrugem.

As avaliações foram realizadas 15 dias após a inoculação. Utilizou-se uma escala de notas adaptada a partir daquela descrita por Van Schoonhoven \& Pastor-Corrales (1987).

Nos ensaios de ferrugem foram observadas diferenças entre as cultivares quanto ao TMP (Tabela 1). Dentre as cultivares recomendadas para Minas Gerais, a Ouro Negro foi a mais resistente, apresentando resistência completa

TABELA 1 - Freqüência de infecção (FI) e tamanho médio de pústulas (TMP)* de cinco patótipos de Uromyces appendiculatus em 17 cultivares de feijoeiro comum (Phaseolus vulgaris)

\begin{tabular}{|c|c|c|c|c|c|c|c|c|c|c|}
\hline \multirow{2}{*}{ Cultivar } & \multicolumn{2}{|c|}{ Patótipo 6} & \multicolumn{2}{|c|}{ Patótipo 7} & \multicolumn{2}{|c|}{ Patótipo 9} & \multicolumn{2}{|c|}{ Patótipo 10} & \multicolumn{2}{|c|}{ Patótipo 12} \\
\hline & FI & TMP & FI & TMP & FI & TMP & FI & TMP & FI & TMP \\
\hline Roxo 90 & 1,1 & $4 *$ & 11,3 & 4 & 18,0 & 4 & 10,5 & 4 & 3,0 & 4 \\
\hline Meia Noite & 5,5 & 4,3 & 10,5 & 4 & 10,5 & 6 & 8,0 & 4 & 0,0 & 1 \\
\hline Jalo EEP & 2,3 & 4,3 & 11,0 & 4 & 5,7 & 4 & 7,5 & 4,5 & 0,2 & 3 \\
\hline Diamante Negro & 2,3 & 3 & 3,7 & 3,4 & 12,7 & 4,3 & 3,0 & 3 & 3,7 & 4 \\
\hline Carioca 1030 & 1,9 & 3,4 & 6,8 & 3,4 & 3,0 & 4,3 & 10,0 & 4 & 2,7 & 4,3 \\
\hline Ouro & 3,0 & 3,4 & 6,7 & 4,3 & 6,7 & 4,3 & 4,7 & 3 & 1,3 & 4,3 \\
\hline Mineiro Precoce & 3,5 & 4,3 & 5,3 & 3,4 & 6,7 & 4,3 & 1,7 & 4 & 0,6 & 4,3 \\
\hline Rudá & 3,7 & 4,3 & 11,0 & 4 & 0,8 & 3 & 0,2 & 3 & 1,2 & 4,3 \\
\hline Milionário 1732 & 5,3 & 3,4 & 0,2 & 3 & 0,2 & 4,3 & 9,7 & 4 & 0,3 & 3 \\
\hline EMGOPA 201-Ouro & 1,4 & 3 & 7,7 & 3 & 3,5 & 4,3 & 0,0 & 2 & 0,0 & 1 \\
\hline Vermelho 2157 & 0,2 & 3 & 10,0 & 4,3 & 0,0 & 1 & 0,5 & 3,4 & 1,1 & 4,3 \\
\hline Pérola & 1,7 & 3,4 & 8,0 & 3,4 & 0,6 & 3 & 0,5 & 3,4 & 0,3 & $4,5,3$ \\
\hline Novo Jalo & 1,1 & 3,4 & 5,0 & 4,3 & 1,7 & 3,2 & 0,0 & 2 & 0,2 & 3,4 \\
\hline Rico 1735 & 4,7 & 5,4 & 0,2 & 3 & 0,5 & 3 & 0,5 & 3 & 0,0 & 1 \\
\hline Carioca MG & 2,5 & 4,3 & 1,1 & 3 & 0,1 & 4,3 & 0,0 & 1 & 0,2 & 3 \\
\hline Aporé & 0,1 & 3 & 0,2 & 3 & 0,2 & 3 & 2,5 & 4,3 & 0,5 & 3,4 \\
\hline Ouro Negro & 0,0 & 1 & 0,0 & 1 & 0,0 & 1 & 0,0 & 2 & 0,0 & 1 \\
\hline
\end{tabular}

* 1- ausência de pústulas, 2- manchas necróticas sem esporulação, 3- pústulas esporulando com diâmetro <300بm, 4- pústulas esporulando com diâmetro de $300 \mu \mathrm{m}$ a $499 \mu \mathrm{m}$, 5- pústulas esporulando com diâmetro de $500 \mu \mathrm{m}$ a $800 \mu \mathrm{m}$, e 6- pústulas esporulando com diâmetro $>$ 800 $\mu \mathrm{m}$ (Stavely et al., 1983). Graus de reação de 1 a 3 indicam resistência e graus acima de 3, suscetibilidade. 
aos cinco patótipos avaliados (Tabela 1). Faleiro et al. (1996) haviam destacado a importância desta cultivar como fonte doadora de genes de resistência em programas de melhoramento. São também importantes as cultivares Aporé, Carioca MG, Rico 1735 e EMGOPA 201-Ouro pela sua resistência a pelo menos três dos cinco patótipos testados.

A maioria das cultivares foi suscetível a pelo menos três dos cinco patótipos testados. As cultivares Roxo 90 e Meia Noite foram as mais suscetíveis à ferrugem. Cultivares extensivamente plantadas no Estado de Minas Gerais, como a Carioca 1030 e a Rudá, mostraram-se suscetíveis, o que justifica a preocupação com o desenvolvimento de variedades de feijão de tipo de grão carioca resistentes à ferrugem.

Faleiro et al. (1999b) avaliaram a resistência de algumas das cultivares recomendadas para Minas Gerais a outros quatro patótipos de $U$. appendiculatus, observando também alta suscetibilidade de Roxo 90 e Meia Noite, bem como de cultivares de tipo de grão carioca como Rudá, Carioca, Pérola e Aporé.

O fungo $U$. appendiculatus apresenta grande variabilidade no Brasil (Carrijo et al., 1980; Mora-Nuñes et al., 1992; Faleiro et al. 1998; Faleiro et al. 1999a). Esta variabilidade tem como conseqüência a "quebra" de genes de resistência a cada safra. Um exemplo desse fato é a cultivar Meia Noite, a qual até 1996 encontrava-se entre as mais resistentes à ferrugem (Faleiro et al., 1996) e, em 1997 mostrou-se suscetível.

A estimativa da FI (Tabela 1) foi importante para confirmar e complementar os dados relativos ao TMP. Pôdese observar que nas cultivares com o TMP superior a $300 \mu \mathrm{m}$ de diâmetro, a FI foi maior.

Nos ensaios de mancha-angular (Tabela 2) foi observado que as cultivares Ouro Negro e EMGOPA 201Ouro comportaram-se como as mais resistentes, apresentando resistência completa a três dos cinco patótipos testados. Os dados indicam que estas duas cultivares apresentam diferentes genes de resistência. Portanto, a hibridação entre as mesmas poderá produzir cultivares resistentes a todos os patótipos testados.

Todas as cultivares testadas foram altamente suscetíveis a pelo menos dois dos cinco patótipos de $P$. griseola. Dentre as mais suscetíveis, podem ser destacadas, além da Roxo 90, outras cultivares extensivamente plantadas em Minas Gerais, como Carioca MG, Pérola, Carioca 1030 e Aporé, todas com o tipo de grão carioca. Dada à importância econômica desse tipo de feijão para várias regiões brasileiras, as quais consomem preferencialmente feijão do tipo carioca, diversos programas de melhoramento tem se preocupado em incorporar genes de resistência à mancha-angular neste tipo de cultivar (Nietsche, 1997a; Sartorato et al., 1999).

Os resultados obtidos neste trabalho permitem concluir que as cultivares recomendadas para o Estado de Minas Gerais não apresentam níveis satisfatórios de resistência múltipla à ferrugem e à mancha angular, indicando a necessidade de uma maior atenção dos programas de melhoramento no
TABELA 2 - Avaliação da resistência de 17 cultivares de feijoeiro comum (Phaseolus vulbaris) a cinco patótipos de Phaeoisariopsis griseola

\begin{tabular}{lccccc}
\hline \hline Cultivar & $\begin{array}{c}\text { Patótipo } \\
\text { 63.55 }\end{array}$ & $\begin{array}{c}\text { Patótipo } \\
\mathbf{3 1 . 2 3}\end{array}$ & $\begin{array}{c}\text { Patótipo } \\
\mathbf{6 3 . 3 9}\end{array}$ & $\begin{array}{c}\text { Patótipo } \\
\mathbf{3 1 . 5 5}\end{array}$ & $\begin{array}{c}\text { Patótipo } \\
\mathbf{6 3 . 2 3}\end{array}$ \\
\hline Roxo 90 & $9 *$ & 8 & 9 & 8 & 7 \\
Carioca MG & 9 & 7 & 7 & 8 & 9 \\
Pérola & 7 & 6 & 9 & 8 & 7 \\
Carioca 1030 & 6 & 8 & 9 & 8 & 5 \\
Vermelho 2157 & 7 & 8 & 7 & 8 & 6 \\
Aporé & 6 & 6 & 8 & 7 & 8 \\
Mineiro Precoce & 8 & 5 & 6 & 8 & 7 \\
Diamante Negro & 5 & 7 & 8 & 7 & 6 \\
Novo Jalo & 7 & 6 & 5 & 8 & 7 \\
Ouro & 5 & 6 & 5 & 7 & 7 \\
Jalo EEP & 5 & 5 & 4 & 6 & 9 \\
Rico 1735 & 7 & 5 & 1 & 9 & 5 \\
Meia Noite & 6 & 1 & 5 & 8 & 6 \\
Rudá & 2 & 2 & 6 & 9 & 6 \\
Milionário 1732 & 2 & 2 & 9 & 8 & 4 \\
Engopa Ouro & 1 & 1 & 7 & 8 & 1 \\
Ouro Negro & 1 & 8 & 1 & 1 & 6 \\
& & & & &
\end{tabular}

* 1 - plantas sem sintomas; 2 - presença de até 3\% de lesões; 3 - até 5\% de lesões não esporuladas; 4- lesões esporuladas, que cobrem aproximadamente $10 \%$ da área foliar; 5 - várias lesões esporuladas entre 2 e $3 \mathrm{~mm}$, entre $10-15 \%$ da área foliar; 6- numerosas lesões esporuladas maiores que $3 \mathrm{~mm}$, entre $15-20 \%$ da área foliar; 7 - numerosas lesões esporuladas maiores que $3 \mathrm{~mm}$, que cobrem entre 20 - $25 \%$ da área foliar; 8- numerosas lesões esporuladas maiores que $3 \mathrm{~mm}$, que cobrem entre $25-30 \%$ da área foliar; 9 - sintomas severos da doença, resultando em queda prematura de folhas e morte da planta (Van Schoonhoven \& Pastor-Corrales, 1987). Plantas que apresentaram graus de 1 a 3 foram consideradas resistentes e as com grau 4 ou maior, suscetíveis.

sentido de desenvolverem cultivares com este tipo de resistência.

\section{REFERÊNCIAS BIBLIOGRÁFICAS}

CARRIJO, I.V., CHAVES, G.M. \& PEREIRA, A.A. Reação de vinte e cinco variedades de Phaseolus vulgaris a trinta e nove raças fisiológicas de Uromyces phaseoli var. typica Arth., em condições de casa de vegetação. Fitopatologia Brasileira 5:245-255. 1980.

DAVISON, A.D. \& VAUGHAN, E.K. Effect of uredospore concentration on determination of races of Uromyces phaseoli var. phaseoli. Phytopathology 54:336-338. 1964.

FALEIRO, F.G., PAULA JR., T.J., BARROS, E.G., FREITAS, M.A. \& MOREIRA, M.A. Resistência de cultivares de feijoeiro comum a Uromyces appendiculatus da Zona da Mata de Minas Gerais. Fitopatologia Brasileira 21:123-125. 1996.

FALEIRO, F.G. Identificação de raças, diversidade genética de Uromyces appendiculatus var. appendiculatus e herança da resistência no feijoeiro. (Tese de Mestrado). Viçosa. Universidade Federal de Viçosa. 65p. 1997.

FALEIRO, F.G., RAGAGNIN, V.A., MESQUITA, A.G.G., 
Resistência de cultivares de feijoeiro-comum à ferrugem...

VINHADELLI, W.S., PAULA JÚNIOR, T.J., MOREIRA, M.A. \& BARROS, E.G. Diversidade genética de isolados de Uromyces appendiculatus utilizando marcadores moleculares RAPD. Fitopatologia Brasileira 23:386-390. 1998.

FALEIRO, F.G., VINHADELLI, W.S., RAGAGNIN, V.A., ZAMBOLIM, L, PAULA JÚNIOR, T.J., MOREIRA, M.A. \& BARROS, E.G. Identificação de raças fisiológicas de Uromyces appendiculatus no estado de Minas Gerais, Brasil. Fitopatologia Brasileira 24:166-169. 1999a.

FALEIRO, F.G., RAGAGNIN, V.A., VINHADELLI, W.S., PAULA JÚNIOR, T.J., MOREIRA, M.A., BARROS, E.G. Resistência de variedades de feijoeiro-comum a quatro raças de Uromyces appendiculatus. Revista Ceres 46:11-18. 1999b.

MORA-NUÑES,.O.A., VIEIRA, C. \& ZAMBOLIM, L. Variedades diferenciadoras de feijão para identificação de raças fisiológicas de Uromyces phaseoli var. typica Arth. Revista Ceres 39:391-404. 1992.

NIETSCHE, S. Identificação de raças de Phaeoisariopsis griseola e determinação de fontes de resistência em Phaseolus vulgaris. (Tese de Mestrado). Viçosa. Universidade Federal de Viçosa. 47p. 1997a.
NIETSCHE, S, CARVALHO, G.A., BORÉM, A., PAULA JÚNIOR, T.J., FERREIRA, C.F., BARROS, E.G. \& MOREIRA, M.A. Avaliação de fontes de resistência de feijão à mancha-angular (Phaeoisariopsis griseola). Fitopatologia Brasileira 22:290. 1997b. (Resumo)

PASTOR-CORRALES, M. A. \& JARA, C. E. La evolucion de Phaeoisariopsis griseola com el frijol comum em América Latina. Fitopatologia Colombiana 19:15-22. 1995.

PAULA JÚNIOR, T.J. \& ZAMBOLIM, L. Doenças. In: VIEIRA, C., PAULA JÚNIOR, T.J. \& BORÉM, A. (Eds.) Feijão: Aspectos gerais e cultura no Estado de Minas. Viçosa. Editora UFV. 1998. pp. 375-433.

SARTORATO, A., NIETSCHE, S., BARROS, E.G., MOREIRA, M.A. SCAR marker linked to angular leaf spot resistance gene in common bean. Annual Report of the Bean Improvement Cooperative 42:23-24. 1999.

STAVELY, J.R., FREYTAG, G.F., STEADMAN, J.R. \& SCHWARTZ, H.F. The 1983 Bean Rust Workshop. Annual Report of the Bean Improvement Cooperative 26:iv-vi. 1983.

VAN SCHOONHOVEN, A. \& PASTOR-CORRALES, M. A. (comps.) Standard system for evaluation of bean germplasm. (CIAT) Cali, Colombia. 1987. 